\title{
Outbreak, Prevalence and Mortality of Severe Acute Respiratory Syndrome Coronavirus 2 (SARS-CoV-2) Infections in Kerala- A Perspective Study ${ }^{\dagger}$
}

\author{
S. Krishnakumar ${ }^{1}$, Aabha Benjamin ${ }^{2}$, G. Prakash Williams ${ }^{3, *}$ \\ 1 Department of Biomedical Engineering, School of Bio and Chemical Engineering, Sathyabama Institute of Science and \\ Technology, Chennai, Tamilnadu, India- 600119 \\ 2 Department of Economics, University College, Thiruvananthapuram, Kerala. India-695034 \\ 3 Post-Graduate Department of Botany and Biotechnology, Bishop Moore College, Mavelikara, Kerala, India- 690110 \\ * Correspondence: prakash.gw@gmail.com; \\ $\uparrow \quad$ Presented at International e-Conference on Bioengineering for Health and Environment (ICBHE 2020)
}

Received: 5.07.2020; Revised: 10.07.2020; Accepted: 12.07.2020; Published: 15.07.2020

\begin{abstract}
Severe acute respiratory syndrome coronavirus 2 (SARS-CoV-2) is the causative agent of infectious disease COVID-19. In India, since the first case reported in Kerala, on January 30, 2020, the outbreak has gradually spread nationwide. The epidemic effect of COVID-19 infection was carried out from January 30 to April 28, 2020 (90 days) across the state. Among the districts studied, Kasaragod and Kannur district exhibit the highest occurrence of COVID-19 cases, whereas Alapuzha and Wyanad districts have the least number of positive cases. The new positive COVID-19 cases were found to be reported in an exponential fashion after 45 days to 75 days, after which there was a decline in the number across the state. As on April 28, 2020, the number of positive cases was 485, recovered cases were 356, active cases were 123 , and the fatal cases were 3 . Among gender, male individuals are more susceptible to COVID-19 infection than female individuals. The number of newly diagnosed patients has been declining, and the epidemic is gradually being controlled.
\end{abstract}

Keywords: Coronavirus; SARS-CoV-2; COVID-19; pneumonia; mortality.

(C) 2020 by the authors. This article is an open-access article distributed under the terms and conditions of the Creative Commons Attribution (CC BY) license (https://creativecommons.org/licenses/by/4.0/).

\section{Funding}

This research received no external funding.

\section{Acknowledgments}

This research has no acknowledgment.

\section{Conflicts of Interest}

The authors declare no conflict of interest. 